\title{
European energy policies and regional burden sharing: what are the effects on the territory of Lombardy?
}

Marcello Magoni*

\begin{abstract}
Introduction: For over a decade, European energy policies have been aimed at obtaining a sustainable and safe supply of energy at competitive prices.

Case description: The EU's targets have been developing over time, up to the definition of a first overall strategy with the approval of the Climate and Energy Package (known as "20-20-20") in 2009. Moreover, the following new targets have been established for 2030 and they are even more ambitious than those agreed for the 2020 Climate and Energy Package: $40 \%$ reduction of greenhouse gas emissions compared to 1990 levels; $27 \%$ of total consumption of energy from renewable sources; $27 \%$ improvement of energy performance. In order to conform to the targets for the production of energy from renewable sources set by the European Union, the Italian Government decided to establish a regional burden sharing with binding commitments for Regions, through the approval of the National Energy Strategy (SEN).
\end{abstract}

Discussion and evaluation: This measure commits Regions to undertake significant operations that may lead to a further boost in the diffusion of RES installations, which will also have an impact on territory.

Conclusion: The article concisely outlines the European and national energy policies and their frameworks and analyzes the effects of burden sharing in Lombardy, as an indicative example of what might happen in the rest of Italy.

Keywords: European energy policy, Renewable energy plants, Energy landscape

\section{European Union energy policies}

National energy policies are significantly influenced by global agreements (such as climate conferences, strategic agreements between energy producing countries and the consumers,...) and strategies (like decisions about the amount of oil to extract, the realization of intercontinental energy infrastructures,...).

Italian strategies, as well as those of any other Member State of the European Union, make reference to European policies on climate and energy (Piebalgs 2006). These are defined according to directives, regulations and financing all aimed at obtaining a sustainable and safe supply of energy at competitive prices.

The current EU's targets are the result of a process which began with the definition of the strategy of the

\footnotetext{
*Correspondence: marcello.magoni@polimi.it

Climate Change, Risk and Resilience Laboratory-DAStU, Dipartimento

di Architettura e Studi Urbani, Politecnico di Milano, Via Bonardi 3,

20133 Milan, Italy
}

Climate and Energy Package approved in 2009. These are known as 20-20-20 targets since, through legislative measures ${ }^{1}$ combining policies regarding the fight against climate change and those regarding energy, they aim to achieve, within 2020 , a reduction by $20 \%$ of greenhouse gas emissions compared to 1990 levels, to produce the $20 \%$ of the total consumption of energy from renewable sources and to improve energy performance by $20 \%$. To those measures, we must add the Directive 2012/27/EU on Energy Efficiency, which regulates a key factor in the achievement of the established targets and that hadn't been considered in the previous 6 legislative measures, even though it had already been pointed out in the Climate and Energy Package. Energy efficiency is actually

\footnotetext{
${ }^{1}$ Renewables Directive (2009/28/EC); Emission Trading Directive (2009/29/EC); Fuel Quality Directive (2009/30/EC); Carbon Capture and Storage Directive (2009/31/EC); Effort Sharing Decision (2009/406/EC); CO2 Regulation for cars (2009/443/EC).
} 
the most cost-effective way in order to reduce emissions, make the supply of energy safer and more competitive and keep the cost of energy down (Moneta et al. 2016).

The importance of operating with a package of integrated intervention strategies to reach the ambitious targets set by the EU, also lies in the fact that those objectives are closely related to each other in several ways. For example, the reduction of energy consumption leads, where energy produced from RES is equal, to an increase of the share of energy produced from RES. And the other way around. Otherwise, to ensure a high reliability level of supply, reduce energy costs and support the most efficient environments, we need to encourage free trade of energy by building efficient infrastructures for energy transportation and storage.

The Directive 2012/27/EU identifies public transport, building, air conditioning and domestic appliances as the industries offering the highest energy-saving potential and sets important objectives and prescriptive measures with significant effects on national and regional energy strategies. These measures include:

- The adoption, by Member States, of long-term strategies to encourage investments in the restoration of both public and private existing residential and commercial buildings;

- The instruction for public utility energy companies to save at least $1.5 \%$ per year of the total amount of energy they sell. This prescription will lead to a modification of these companies' business models since they will not just have to provide electricity, gas or fuel, but a service for heating, lighting and making cars and domestic appliances work;

- The restoration of $3 \%$ of buildings owned or occupied by central governments per year;

- The obligation for large companies to undergo energy audits at least every 4 years;

- The obligation for every building unit connected to centralized heating and cooling systems to get heat and cold accounting consumption systems by 31 December 2016.

Directive (2010/31/EC) strengthened the measures for consumption reduction for the construction industrythis being responsible for about $40 \%$ of the total consumption of energy and 36\% of the climate changing emissions in Europe-by replacing the energy proof certificate for buildings with the energy performance certificate, expanding the evaluation to the whole building consumptions and, above all, by defining new minimum requirements of energy performance for new buildings. That is to say that, from 31 December 2018 new buildings owned and occupied by public administrations, including schools, will have to be near zero energy consumers and from 1 January
2021 this will concern private buildings too. These buildings will also guarantee covering for a significant share of the energy demand from renewable sources. Lastly, Member States must elaborate national plans and define policies aimed at enhancing the conversion of renovated buildings into near zero energy consuming buildings.

The European Union has extended its climate and energy objectives to 2050 and made them much more ambitious through further measures, like the "Energy Roadmap 2050". If we extended the strategies we are using for achieving the 2020 targets to 2050, we would get a reduction of consumption slightly above $30 \%$, while the strategy set by the European Union established a reduction in a range between 80 and $95 \%$ as a result of international agreements. An intermediate step, meant to respond to the uncertainties of governments, entrepreneurs and citizens, also considering the economic and technologic development of the last few years, has been set for 2030 with the aim of reducing greenhouse gas emissions by $40 \%$ compared to 1990 . This objective is associated with an increase in the renewable energy share, that will have to reach at least $27 \%$ and to the achievement of an energy efficiency level of $27 \%$.

European policies regarding energy are strongly directed to the decarbonization of its energy systems and they are now the most ambitious in the world, both in the long and the short term (more than the ones recently approved by the US). This requires and will require a great effort by Italy in order to meet these targets; as of today however the targets have been achieved, even though their accomplishment has been influenced by the "favorable" scenario of the national and international economic and production crisis (Chiesa 2017).

\section{National energy strategy}

In order to direct and organize general decisions for the Italian energy policy, the National Energy Strategy (SEN-Strategia energetica nazionale) was instituted (Legislative Decree No. 112/08). It responds to Directives 2009/28/EC and 2012/27/EU; the former is about the promotion of renewable sources and commits Member States to the adoption of a national action plan for renewable sources; the latter concerns energy efficiency and requires every Member State to edit a national action plan for energy efficiency by 2014.

The current National Energy Strategy was approved by the Ministry of Economic Development and the Ministry of the Environment and for Protection of the Land and Sea by means of the Decree of 8 March 2013 and it focuses on four macro-objectives.

The first objective consists in the reduction of the differences in the cost of energy for Italian consumers and companies at the lowest average European costs, 


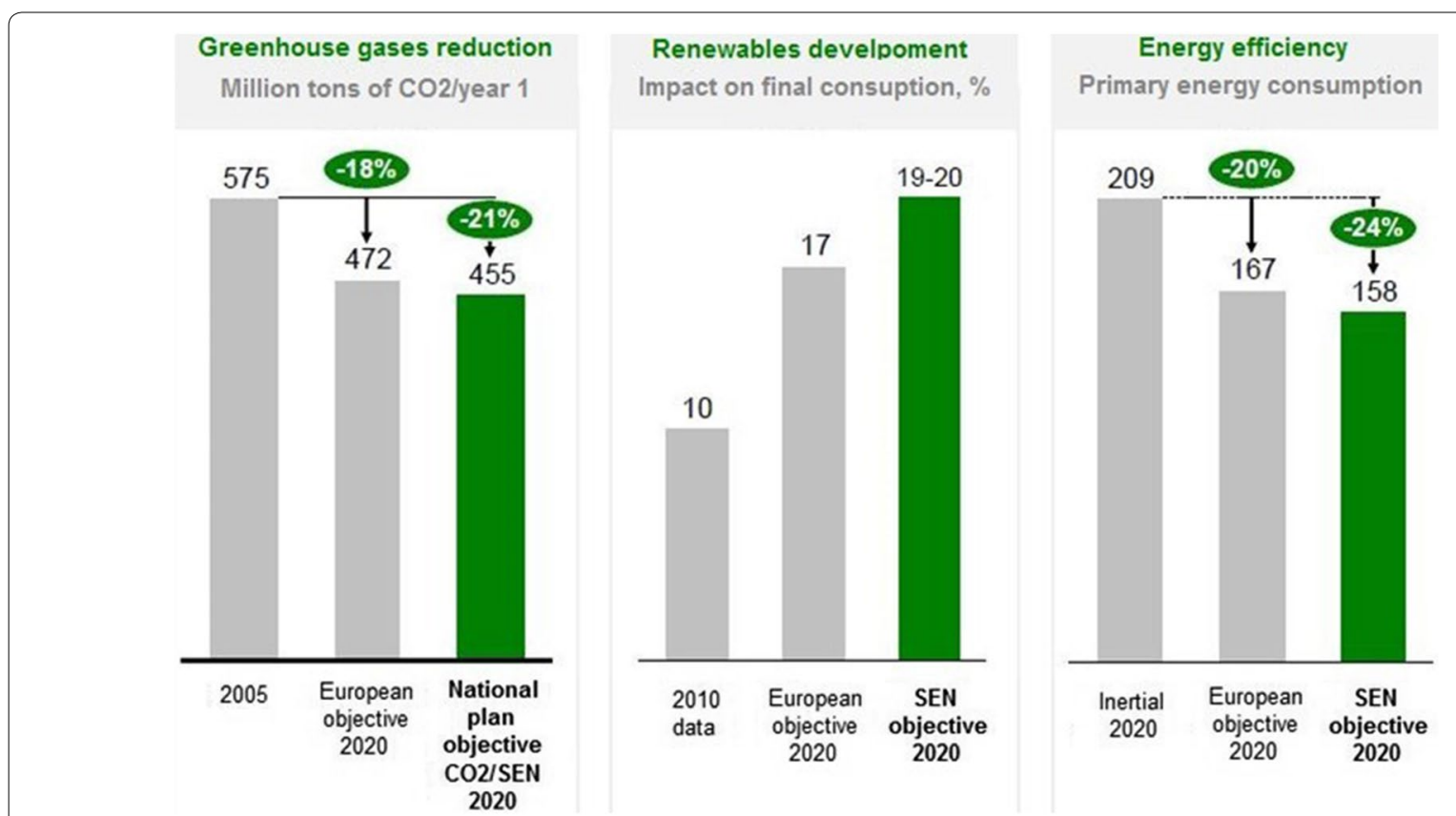

Fig. 1 Main objectives of the National Energy Strategy for 2020 (Source: SEN, II superamento degli impegni ambientali europei al 2020, page 35 table 13)

beginning with the development of an improved electricity market fully integrated with the European one, with competitive prices and a strong integration of the production of renewable energy. The reduction of energy costs implies a series of actions with significant effects on territory. These actions include: the extension and improvement of the electricity grid, which would permit a greater electrification of the transport industry, a greater use of geothermal heat pumps, the renovation of the refining sector and the sector of fuel distribution and the improvement of the national production of hydrocarbons, especially in the Adriatic Sea.

The second objective consists in reaching and even exceeding the targets defined by the Climate and Energy Package 2020 (see Fig. 1) by immediately trying to focus on getting to the decarbonization scenario outlined in the "Energy Roadmap 2050" and expecting a verification of energy strategies in 2030. In particular, we expect to reach more ambitious targets compared to those set by Europe for Italy. For example, a further 3 points reduction of greenhouse gas compared to the $18 \%$ target, renewable sources reaching the share of $20 \%$ of final consumption of energy ${ }^{2}$ compared to the $17 \%$ target, a

\footnotetext{
2 "Final consumption of energy" meaning: the energy commodities delivered for energy purposes to manufacturing industry, transport, households, services, agriculture, forestry and fisheries, including the consumption of electricity and heat by the energy branch for electricity and heat production and including losses of electricity and heat in distribution (see Directive 2009/28/EC).
}

further $4 \%$ reduction of primary consumption compared to the $20 \%$ target.

The third objective consists in improving supply safety, especially for gas, reducing imported energy from 84 to $67 \%$ of the total amount and saving 14 billion euros compared to the current 62 billion spent for energy importation. This strategy points towards creating a competitive gas market through significant infrastructural interventions (gasometers, gas pipelines and storage areas) that might lead to the building of the main gas hub in southern Europe.

The fourth objective consists in supporting a sustainable economic growth through the development of the energy sector. More specifically, this means to promote new investments for 180 billion euros from now to 2020 , to be used both for the improvement of renewable sources and energy efficiency and for upgrading traditional sectors such as electrical grids, regasification, storage and hydrocarbons. This fourth objective is a compromise between the need to de-carbonize the Italian economy and the need to reduce external reliance for fossil fuels. Therefore, in the long transitional period towards a low carbon emission economy, the aim is to substitute fossil sources coming from abroad with those located on the national territory.

Even the National Energy Strategy recognizes energy efficiency as a top priority, since it aims at reaching all the cost, competitiveness, safe supply and environment 
Table 1 Gross final consumption paths in Italy and regional objectives from the year of reference to 2020. Source: Ministerial Decree of 15 March 2012)

\begin{tabular}{llccccc}
\hline & Reference year & $\mathbf{2 0 1 2}$ & $\mathbf{2 0 1 4}$ & $\mathbf{2 0 1 6}$ & $\mathbf{2 0 1 8}$ & $\mathbf{2 0 2 0}$ \\
\hline $\begin{array}{c}\text { Gross final consump- } \\
\text { tion (ktoe) }\end{array}$ & 136.712 & 132.049 & 132.298 & 132.546 & 132.749 & 133.042 \\
$\begin{array}{c}\text { Regional objectives } \\
(\%)\end{array}$ & 5.3 & 8.2 & 9.3 & 10.6 & 12.2 & 14.3 \\
\hline
\end{tabular}

For electricity RES, the initial reference value is the national gross electricity production from renewable sources of 2009, measured by Gse and calculated according to Directive 28/2009. For heating RES, the initial reference value is the national consumption from renewable sources for heating/cooling of 2005 provided by Enea

targets at once. However, there are several barriers that make its implementation difficult in Italy (VV. AA 2017), for example:

- High up-front investment costs, lack of awareness of potential saving, difficulty in accessing incentives in civil matters;

- Impossibility to access tax deductions, difficulty in self-financing and in the penetration of the Energy Service Company (ESCO) model in Public Administration. The promotion of Public Administration intervention only saw the light with the introduction of the Thermal Energy Account;

- Limited availability in industry of internal competences and of professionals specialized in the realization of complex interventions that often imply longterm financial return processes.

In order to favor the implementation of efficient solutions, the National Energy Strategy intends to rationalize and improve the already existing legislative instruments in order to promote scarcely considered market segments. These measures consist in:

- The establishment of minimum standards for the building industry (new buildings and large-scale refurbishments), for high-efficiency cogeneration and for transport;

- The extension in time, the correction and the improvement of tax deductions for energy saving interventions in the construction industry (also known as " $55 \%$ measure");

- The introduction of direct incentives for energy efficiency interventions in Public Administration (Thermal Account);

- The improvement of the Energy Efficiency Certificates system, by increasing the offer and including new sectors and intervention areas.

Besides the legislative instruments, the National Energy Strategy identifies some key factors for the implementation of the energy efficiency program: strengthening the Energy Service Company (ESCO) model, improving and monitoring intervention measures, making users (citizens, companies and Public Administration) more aware through communication programs, supporting research and innovation, implementing energy planning and urban sustainable development measures.

\section{Regional burden sharing}

The target set by Europe of reaching the 20\% of the gross final consumption of energy from renewable sources by 2020 , was distributed between the Member States according to their GDP per capita; a 17\% share was established for Italy.

In the National Action Plan for Renewable Energies presented by Italy in Brussels in June 2010, the Italian share was divided between the different energy sectors according to technical and economical evaluations. The electricity sector will have to reach at least $26 \%$ of production of energy from renewable sources, $17 \%$ was established for the thermal sector and 7\% for the transportation sector. Since these percentages refer to total expected consumption and not to real consumption in the reference year (see Table 1), the achievement of these objectives will be influenced by possibly contrasting technological and socio-economic dynamics. For example, an increase in final energy consumption could be registered even when steps towards energy efficiency are taken; conversely, consumption could decrease due to economic recession phases or favorable weather conditions despite the lack of investments in energy efficiency.

The national objectives are minimum objectives that may be integrated and further developed through twoyear updates, in order to consider technological changes, greater or lower contribution of energy sources and the results of monitoring.

The Ministerial Decree for Economic Development of 15 March 2012 introduced the "burden sharing" measure for every Region and Autonomous Province for the production of energy from renewable sources (see Table 1), which indicates the minimum share of energy (electricity, 
Table 2 Gross final consumption paths in Lombardy from the initial situation to 2020

\begin{tabular}{|c|c|c|c|c|c|c|}
\hline & Reference year $^{a}$ & 2012 & 2014 & 2016 & 2018 & 2020 \\
\hline Objectives (\%) & 4.9 & 7.0 & 7.7 & 8.5 & 9.7 & 11.3 \\
\hline $\begin{array}{l}\text { Gross final consumption } \\
\text { (ktoe) }\end{array}$ & 26.485 & 25.593 & 25.647 & 25.701 & 25.756 & 25.810 \\
\hline
\end{tabular}

See footnote of Table 1

a The initial reference value is obtained through the sum of the following regional consumptions: regional gross electricity production from renewable sources of 2009 , measured by Gse and calculated according to Directive 28/2009 and regional RES consumption for heating/cooling of 2005 provided by Enea

heating and transportation) that has to be produced from renewable sources to contribute to the national $17 \%$ objective of gross final consumption by 2020 . However, regions were only given $14.3 \%$ of the final gross consumption, since the national share for the consumption of biofuels used for transportation and for importing renewable energy from Member States and third countries is not included in their share. Regional shares may vary even due to the update of the objectives of the Action Plan.

The Ministry of Economic Development will verify the share of final gross consumption covered by renewable source every year and for each Region and Autonomous Province. From 2016 the intermediate objectives will become binding and, in case a Region does not achieve them, from 2017, on the basis of data from 2016, the Government might intervene, even by nominating a commissioner.

The extent of the intervention varies according to the energy sector. For electricity RES, the consumption in the year of reference is 5380 ktoe, while the 2020 objective is 8504 ktoe, so an increase by 3124 ktoe is necessary, which represents the $58 \%$ of the consumption in the year of reference. For thermal RES, reference consumption is 1916 ktoe and the 2020 objective is $10,506 \mathrm{ktoe}$, so an increase by 8590 ktoe is necessary, which means $448 \%$.

The share set for Lombardy amounts to $11.3 \%$ (see Table 2), which means that electricity RES will have to produce 1090 ktoe in absolute values, with an increase by 97 ktoe, 10\% compared to the reference consumption of 993 ktoe. Thermal RES will need to produce 1815 ktoe, with an increase by 1499 ktoe, $476 \%$ compared to the reference consumption of 315 ktoe. This difference in objectives will imply greater economic and technologic investments in RES in the next few years, a strategy that has been employed by Europe and by nations for the past couple of years.

Table 2 also indicates the path to 2020 of final gross energy consumption shares, calculated as a sum of electrical and non-electrical contributions that containment policies will have to achieve. Obviously, if final consumptions decreases, the objective of increasing the total share of energy from renewable sources will be easier to reach.
The Regional Environmental Energy Plan (PEAR) of Lombardy - the designed instrument for the actuation of strategies in order to achieve the regional burden sharing objectives-considers renewable energies, not just as a sustainable development factor, but also as a propulsive factor for the economy of Lombardy, with the aim of covering a greater final consumption share compared to the one established by the burden sharing. The reference economic model for the energy sector is in fact going through a deep transformation towards greater efficiency and a greater use of small RES plants; this transformation is due to the reduction of the economies of scale in the production of energy, to the availability of control systems for low cost networks, to the need of improving environmental performances and supply safety for this sector.

In order to reach the burden sharing objective in Lombardy, the production of energy from renewable sources should achieve about 2.9 mtoe. If we consider that in 2012 the share of final consumption covered by renewable sources was $10.1 \%$, (2.4 mtoe), we can immediately see that the objective can be easily achieved. On the other hand, the aim of the Regional Environmental Energy Plan is to beat the one set by the burden sharing; two different scenarios have been hypothesized: in the best scenario, the total contribution by RES will reach about 3.9 mtoe, while in the intermediate scenario it will get to about 3.2 mtoe. This means that in the period from 2013 to 2010 the further production of RES should swing between a minimum of 5 mtoe and a maximum of 15 mtoe.

The PEAR aims at a strong improvement in thermal RES, since they are underused compared to their potential. Significant measures towards the transition to electric mobility are expected, although they will be completed only after 2020 .

\section{Territorial effects of RES installations diffusion strategies in Lombardy}

The strategic goal of improving the thermal sector, even by setting higher standards for new buildings and the anticipation of the obligation to build zero-consuming 
buildings, implies a significant diffusion of solar panels and biomass plants.

Solar thermal technology has reached high levels, with quite easy installation processes and the energy capture system has become a structural element in new buildings (Thirugnanasambandama et al. 2010; Shukla et al. 2013). Moreover, the development of innovative plants we saw in the past few years, to begin with different kinds of heat pumps (aero/hydro/geothermal) and the ability to industrialize high-temperature thermal plants, could lead to providing heating for big tertiary and industrial users.

Solar heating plants are usually integrated into buildings so they don't imply significant territorial effects, except when they are installed on existing buildings.

Biomasses represent an advanced industry with a great development potential, both quantitative, through efficiency raising processes and the sustainable use of the biomass available in the territory of Lombardy, and qualitative, through the activation of the bio-methane production supply chain (Berndesa et al. 2003).

The PEAR promotes the construction and improvement of cogeneration district heating systems fueled by combustion of biomass or by anaerobic digestion of biogas, in rural and mountain areas; here biomass availability is high and energy demand is low, so it requires small and medium-size plants. These interventions usually fit in well with territory, since they are quite small and they can be easily located in the productive areas of the main inhabited centers. Where this is not possible, there could be negative effects on mobility and landscape.

A significant increase of the thermal energy share is expected to be obtained by co-generative plants linked to anaerobic digesters, which will not produce any relevant effect on the territory, both in the case they are built upon existing plants (only requiring to move pipes underground), both when they have to be set in different locations, with the digester positioned at the farm and the co-generator near thermal utilities, in order to reduce costs by only moving gas pipes underground, which is cheaper.

Heating transportation networks could also be used for recovering waste heat, since in Lombardy there are many potential sources of waste heat due to industrial and thermoelectric power plants. In this case, innovative, low-heat, small-scale district heating system networks are built; not only they use RES (geothermal, solar,...), but they can become accumulation systems from which users can draw thermal energy.

The use of high-quality wood fuels (like pellets), which is getting necessary in order to reduce PM10 emissions and improve energy efficiency of wood biomass, is also a chance to revitalize and develop local industries based on networks of plants spread throughout territory, among which the facilities for the collection of municipal waste. These installations can be easily located in the productive areas of the main towns and only when this is not possible, there could be negative effects on mobility and landscape.

The production of biomethane has been a crucial topic both at national and European level, since it can be easily obtained by purifying biogas and it can be pumped into the network without blending, in order to serve domestic and industrial users or methane distributors. This process implies a further diffusion of anaerobic digestion plants in rural areas-usually characterized by short-chain supply systems powered by animal manure, agricultural waste and energy cropsor industrial areas (Bertagna and Marini 2011). The realization of plants for the production of methane in rural areas will imply a further modification of their features in a multifunctional way, where energy, including energy crops and food crops waste management processes, will represent an increasingly significant productivity factor at both economical and visual level.

Within the next decade a wider diffusion of biomethane supply points is expected, since the EU Directive for the development of energy infrastructures and alternative fuels has established that an appropriate number of methane plants, according to the increasing demand, will have to be built in urban and extra-urban nodes by 2025. Lombardy has imposed the presence of methane pumps in new service stations (regional law 24/2006), providing a discrete diffusion of refueling points. Producing biomethane by using part or all of the organic solid urban waste, would allow to produce pumps for fueling vehicles for waste collection.

Multifunctional farms start from agricultural products to get to the production of food, fertilizers, chemicals, energy products and to bio-refining; this is a further development for the production of RES, since it considers the whole process of transformation from raw materials to finished products. Moreover, the development of bio-refineries could lead to an enhancement in the use of vegetable raw materials, from which substances get extracted on a decreasing added value basis up to the point where even final waste can be used for energy purposes (Cherubini and Strømman 2011). This kind of industry, which is quite widespread throughout territory, involves both biomass producers (farms, food and paper factories, biomass waste producers) and users of bio-refinery products like food, feedingstuff, chemical and pharmaceutical companies.

Electricity RES will see a smaller-scale development compared to thermal energy RES.

Photovoltaic technologies have been suffering a slowdown during the past couple of years, due to the 
interruption of the funding flow for the Fifth Energy Account. Despite this, it is assumed that plants have been installed for $2600 \mathrm{MW}$.

The hydroelectric sector has a low growth-margin compared to its power in use (Terret and Marca 2016). It is expected to grow by $230 \mathrm{MW}$ (5\% of the current amount), considering potential diversion concessions, the repowering of existing plants and the realization of small plants on branch canals and aqueduct waterfalls. In case of prolonged periods of heavy rain due to climate change, there is the need to adequately manage every single flood storage in order to maintain the current hydroelectric productivity levels. The installation of new branches will require significant territorial modifications; these are favored by the current regulatory framework, since tax incentives are inversely proportional to power, which draws the market towards solutions characterized by lower efficiency and greater impact.

One of the main territorial effects linked to the use of renewable energy sources, regards the current national transport network improvement plan, necessary to avoid limiting the exploitation of the production capacity of RES plants, whose energy production can't be programmed. These interventions consist in the improvement of the capability of transformation from high to low voltage, which implies the construction of new primary cabins and the upgrade of the already existing ones along with the reinforcement of the medium voltage-power network through the realization of new power lines. Plus, the so called "merchant lines" will be built; these are private transmission lines that in Lombardy should cover a total length of $100 \mathrm{~km}$.

Another fundamental infrastructure for the exploitation of RES is the one used for charging electric vehicles; this kind of infrastructure will spread exponentially, since every European Union Member State will have to grant covering their urban and extra-urban nodes by 2020 with an appropriate number of charging stations for electric cars; within 2025 every motorway tract in Europe will have to be covered as well. In general, territorial effects will be quite limited, since charging stations will be placed in private or public parking lots in residential, commercial and industrial areas or in service stations in the main roads.

In general, territorial effects produced by Lombardy's energy strategies highly depend on the kind of response that the interested subjects will have to energy production and usage. One of the options is to build a high number of small and medium plants that more or less fit in the buildings and areas they are located in; another option is to build a small number of large and medium plants, which are harder to integrate into territory.

Authors' contributions

The author read and approved the final manuscript.

Competing interests

The author declares that there is no competing interests.

Availability of data and materials

Not applicable.

Consent for publication

Not applicable.

Ethics approval and consent to participate

Not applicable.

Funding

Not applicable.

\section{Publisher's Note}

Springer Nature remains neutral with regard to jurisdictional claims in published maps and institutional affiliations.

Received: 31 July 2018 Accepted: 27 September 2018

Published online: 01 October 2018

\section{References}

Berndesa G, Hoogwijkb M, van den Broek R (2003) The contribution of biomass in the future global energy supply: a review of 17 studies. Biomass Bioenergy 25(1):1-28

Bertagna A, Marini S (2011) The landscape of waste. Skira, Milano

Cherubini F, Strømman AH (2011) Chemicals from lignocellulosic biomass: opportunities, perspectives, and potential of biorefinery systems. BIOFPR 5:548-561

Piebalgs A (2006) Green paper: a European strategy for sustainable, competitive and secure energy, CESifo Forum, Ifo Institut für Wirtschaftsforschung an der Universität München, München. 7(2):8-20

Shukla R, Sumathy K, Erickson P, Gong J (2013) Recent advances in the solar water heating systems: a review. Renew Sustain Energy Rev 19:173-190

Terret A, Marca F (2016) Prospective future dell'idroelettrico in Italia. Thesis, Politecnico di Milano, 28 September 2016, AY 2015/2016

Thirugnanasambandama M, Iniyanb S, Goic R (2010) A review of solar thermal technologies. Renew Sustain Energy Rev 14(1):312-322

Moneta R, Bertini I, Di Franco N, Federici A (2016) Italy's energy efficiency annual report, 2016 executive summary (www.enea.it)

Chiesa V (editor) (2017) Renewable energy report, energy and strategies group, Politecnico di Milano 